\title{
Assessment of the Probabilities that Staff and/or Patients Will Detect Fires in Hospitals
}

\author{
DAVID A. CHARTERS \\ NHS Estates \\ 1 Trevelyan Square \\ Boar Lane, Leeds, LS1 6AE, UK \\ JONATHAN R. BARNETT, MICHAEL SHANNON, \\ PETER HARROD, DANIEL SHEA and KEVIN MORIN \\ Centre for Firesafety Studies \\ Worcester Polytechnic Institute \\ 100 Institute Road \\ Worcester, MA 01609-2280, USA
}

\begin{abstract}
This paper describes how fault tree analysis may be used to calculate the probability that people will detect fires in hospitals. In particular, study is made of the contribution of patients and varying staff numbers. Their contribution is based on new data gathered by shadowing staff and assessing wards. This data showed that staff spent 75 per cent of their time undertaking duties that would facilitate the detection of fires, in locations where they could observe more than 30 per cent of the ward. This provides a greater understanding why the historical data indicates that staff observation of fire is so effective. It is concluded that fault tree analysis offers a useful tool which can inform decisions regarding the cost/benefit of fire protection measures.
\end{abstract}

KEY WORDS Fault tree analysis, fire detection, hospital fire safety, observation by people, probability.

\section{INTRODUCTION}

Fire safety is one of the greatest challenges facing the designers and operators of healthcare premises. This is particularly true where patients are highly dependent on staff eg the elderly, mentally ill, those in intensive care, surgical theatres ...etc. The lack of alertness, lack of mobility and high dependency on fixed equipment of these patients have obvious implications for their safety in the event of a fire. 
The UK standard for hospital fire safety; FIRECODE [2] was therefore developed. The fire safety strategy embodied in FIRECODE is based primarily in the avoidance of fire. In its event, there should be means for rapid detection, containment and control, supported by reliable and well rehearsed procedures for removing patients to places of safety. Figure 1 shows the layout of a typical ward.

Much effort has been devoted by fire safety scientists to understanding the detection of fires by automatic fire detection systems. The result of this work allows some understanding of how fire detectors function in the room of fire origin and adjacent areas. However, the detection of fire by people has not been studied in such detail and is a strongly probabilistic phenomenon. McCormick [1] and Finucane and Pinkney [8] have demonstrated how the reliability of fire protection systems can be modelled using fault trees and how fault tree analysis can be applied to address fundamental fire safety issues.

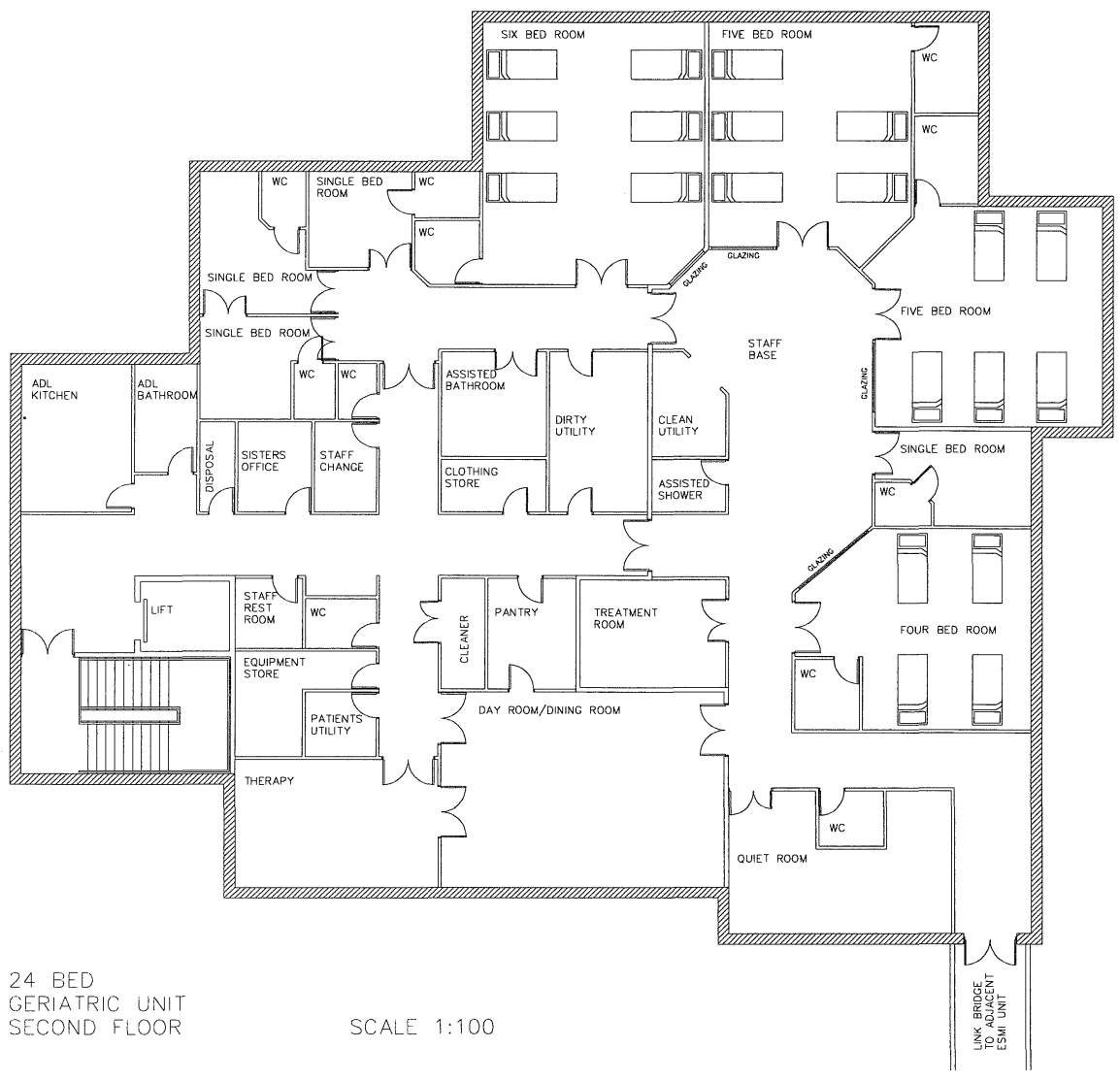

Figure 1 : Layout of typical hospital ward 
Clearly, the level of automatic fire detection and number of people play a significant role in the process of rapid warning of fire [3]. Generally, each department or ward is divided into a number of sub-compartments. Where sub-compartments enclose patient bedded areas and contain 24 hour staff bases the primary means for detection of fire is people. Conversely, where sub-compartments enclose support or service areas such as staff rooms and offices these are covered by automatic fire detection. For the layout in Figure 1, the bedded areas are generally to the top and right and the support areas are generally to the bottom and left.

One of the most crucial elements of the success of the observation of fires by people in general and staff in particular, is the layout of the ward. Patient beds should be positioned and partitioned such that as high a proportion as possible (consistent with clinical care and privacy) are visible from the staff base. Historical data shows that 86 per cent of patient care area fires are detected within five minutes of ignition [5,6]. Similarly, data indicates that 64 per cent of fires were detected by staff, 21 per cent by automatic fire detectors and only 5 per cent were detected by patients [5]. The low proportion for patients may be because when staff are alerted by patients the means of detection is attributed to staff. However, it is not clear why the detection of fires in patient access areas is so effective and in particular why the contribution by staff is so significant. Variables associated with the detection of fire by staff include; their number, distribution, the ward layout, type of task etc.

The following analysis uses existing approaches to modelling fire detection by fault tree analysis [1] to evaluate the contribution made by staff observation. The approach demonstrates how the most reliable and cost-effective fire detection specification [7] can be determined for specific applications.

\section{ANALYSIS}

\section{Construction of the fault tree}

Figure 1 shows the floor plan of a typical hospital ward. The ward is divided into two areas; the patient bedded area and the service area. Fires may be detected by automatic fire detectors or by patients/staff. The time period in which staff (first aid fire-fighting and/or patient evacuation) intervention in a fire situation is feasible is typically 5 minutes after ignition and this is taken as one of the collection criteria for fire report data. Therefore, a fault tree was constructed taking these factors into account.

Figure 2 expresses this logical hierarchy in the form of a simple fault tree [7]. The top event is the event of concern which is linked through a series of intermediate events and logic gates to four base events. To quantify the conditional probability of the top event, data is required for all the base events. This assumes that the probability of a fire occurring is the same in all parts of the ward. Statistics indicate that is not the case and this is explored further in the discussion.

\section{Fault tree analysis}

Once the fault tree has been established, the next step is to determine some means of quantifying the top event. For more complex fault trees this is done typically by Boolean reduction to a 
'minimum cut set' which can then be quantified. Boolean algebra governs the mathematics of logic processes. Boolean reduction involves the combination of terms to produce the simplest algebraic expression of the most significant terms - " a minimum cut set". However, for this simple tree Boolean reduction is not possible. Thus the probability that in the event of a fire there will be a 'failure to detect the fire on a ward within 5 minutes', $\mathrm{P}_{\mathrm{f}}$ is:

$$
\mathrm{P}_{\mathrm{f}}=\left(\mathrm{P}_{\mathrm{A}}+\mathrm{P}_{\mathrm{B}}-\mathrm{P}_{\mathrm{A}} \cdot \mathrm{P}_{\mathrm{B}}\right) \cdot\left(\mathrm{P}_{\mathrm{C}}+\mathrm{P}_{\mathrm{D}}-\mathrm{P}_{\mathrm{C}} \cdot \mathrm{P}_{\mathrm{D}}\right)
$$

A certain amount of work has been undertaken on three of the base events in the event tree. Therefore, the values of $\mathrm{P}_{\mathrm{A}}, \mathrm{P}_{\mathrm{B}}$ and $\mathrm{P}_{\mathrm{C}}$ for the generic situation can be found.

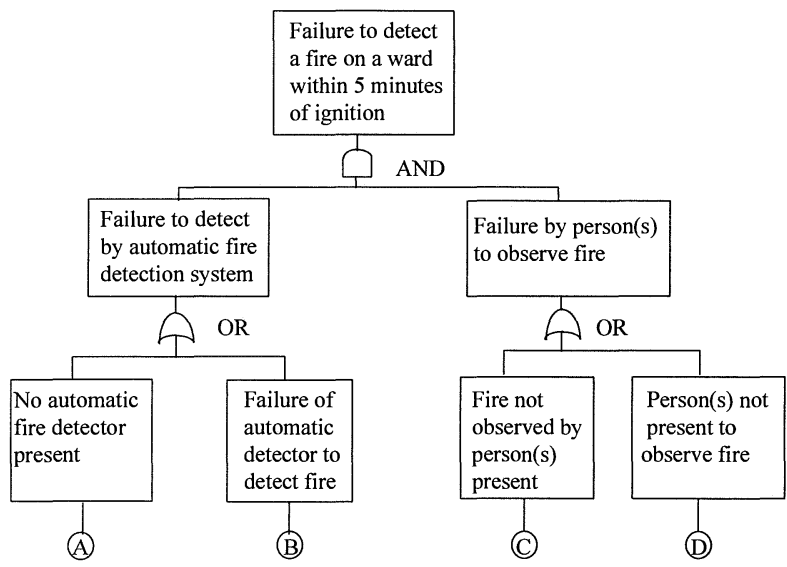

Figure 2 : Fault tree for detection of fires in hospital wards

Analysis of the design of various hospital designs and the requirements of FIRECODE [2] indicate that the average proportion of the ward directly covered by automatic fire detection systems is approximately 20 per cent. If conservatively, we neglect the detection of fires in adjacent areas, the conditional probability that there will be 'no automatic detector present', $\mathrm{P}_{\mathrm{A}}$ is 0.8 .

The reliability of automatic fire detection systems has been the subject of much investigation over the years. Finucane and Pinkney [8] estimated that the failure on demand of an automatic detector in an industrial/office environment varied between 0.01 and 0.1 . Hospitals, by their nature, tend to be relatively clean and there are strict requirements for the inspection and maintenance of automatic fire detection systems. Therefore, again conservatively, we could take the conditional probability of the 'failure of an automatic detector to detect a fire', $\mathrm{P}_{\mathrm{B}}$ as 0.1 . This assumes that failure of the rest of the automatic fire detection system and unavailability for 
repairs are negligible. Relative to the value of 0.1 , the data presented by Finucane and Pinkney supports this assumption.

Although, there is no data on hospital person(s) failing to detect a fire, much work has been undertaken in the process industry on the efficacy of control room staff observing abnormal conditions on complex plant [9]. Therefore, a conservative (ie pessimistic) figure of 1 in a thousand is used in most safety cases and empirically it seems highly unlikely that a staff member in a position to observe a fire is not going to become aware of it within 5 minutes. Therefore, the value of the conditional probability that a 'fire will not be observed by staff $\mathrm{P}_{\mathrm{C}}$ can be taken as $1 \times 10^{-3}$.

There is little, if any, data on the conditional probability that 'staff will not be present to observe a fire' and there is no other situation where equivalent data may be relevant. As part of this study, an investigation was undertaken to record the distribution of nursing staff and their propensity to observe a fire in a ward for types of layout (giving different degrees of visual access), patient types, and types of shift. Table 1 shows an outline of the data collected.

\section{TABLE 1 - Data Collection}

\begin{tabular}{||l|l||}
\hline \hline Patient type & 5 types \\
\hline Ward layout & 4 types \\
\hline Task type & $\begin{array}{l}\text { Skill based (low concentration) } \\
\text { or } \\
\text { Knowledge based (high concentration) }\end{array}$ \\
\hline \% of ward observable & $0-10 \%$ \\
$\downarrow$ & $90-100 \%$ \\
\hline Patient alertness & $>50 \%$ alert \\
& or \\
& $<50 \%$ alert \\
\hline Shift start time & $24 \mathrm{hr}$ clock \\
\hline Shift Duration & $0-8 \mathrm{hrs}$ \\
& $1-10 \mathrm{hrs}$ \\
$2-12 \mathrm{hrs}$
\end{tabular}

Individual staff members and patients were "shadowed" and their ability to observe a fire involved was recorded at 15 minute intervals. The ability of staff to observe a fire involved a subjective judgement by the individual shadowing the member of staff based on knowledge of 
the likely growth rate and development of several types of ward fire. Staff were aware of the broad thrust of the study but not the specific objectives. The data was collected for over 300 staff hours and the overall analysis of this data provided the following average probability distribution for one staff member and one ward of patients [10].

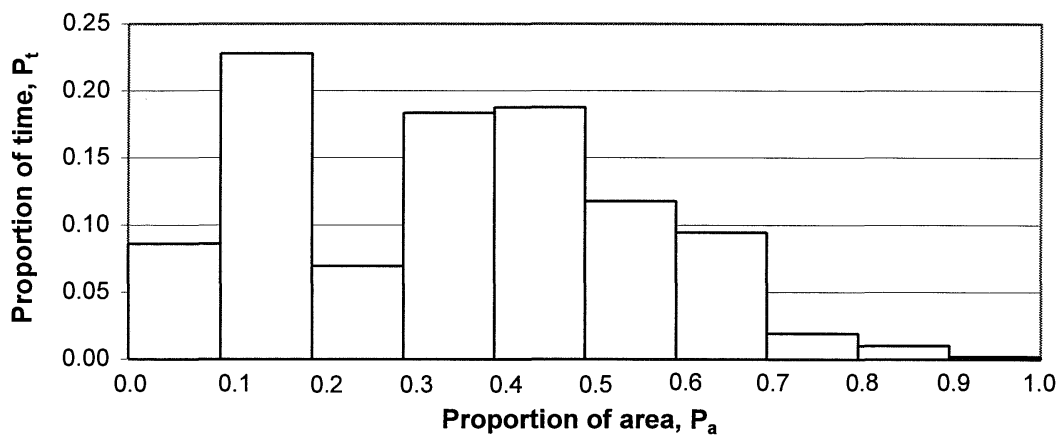

Figure 3 - Observation probability distribution for case 1 - one staff

Figure 3 is the probability distribution that a member of staff will be in a position to observe a fire in a certain proportion of the wards area, $\mathrm{P}_{\mathrm{a}}$ for a certain proportion of the time, $\mathrm{P}_{\mathrm{t}}$. The distribution shows two peaks. The first at values of $\mathrm{P}_{\mathrm{a}}$ between 0.1 and 0.2 is when staff are undertaking tasks in small rooms such as stores and kitchens or more often when treating patients and curtains are drawn to provide privacy. The second peak between values of $\mathrm{P}_{\mathrm{a}}$ of 0.3 and 0.5 occurs when staff are undertaking general duties at or around the staff base where observation is generally good.

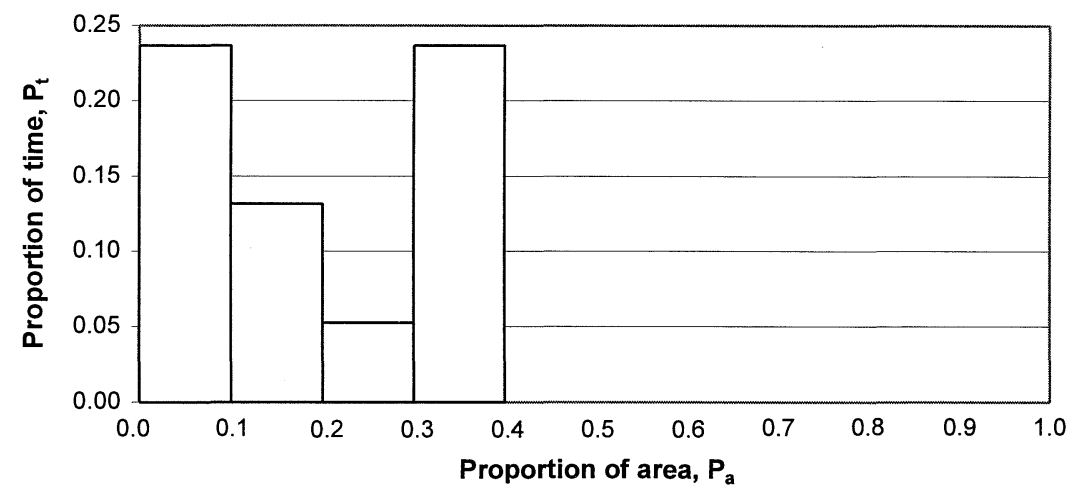

Figure 4 - Observation probability distribution for Case 2 patients 
Figure 4 shows a similar distribution for patients who were alert and able to raise the alarm. The first of the two peaks at $\mathrm{P}_{\mathrm{a}}$ between 0.0 to 0.1 represents patient accommodation in single bedded rooms. That is, for approximately 24 per cent of the time when patients are alert and able to raise the alarm, they are in small rooms or have curtains drawn around the bed for privacy. The second peak represents patients in four or six bedded bays where they do not have the same high level of observation as staff from the nurse station but all the same can survey a fairly wide area.

The overall probability that a member of 'staff will not be present to observe a fire', $\mathrm{P}_{\mathrm{D}}$ is given by:

$$
P_{D}=1-\Sigma\left(P_{t}, P_{a}\right)
$$

The same relationship may be applied to probability that patients will be present and alert to observe a fire.

The standards for staff numbers in FIRECODE and the data collected on staff distributions indicated that there were generally two or more staff on a ward at any point in time. To quantify the fault tree and draw useful conclusions we need to be able to combine the probability distributions to represent standard, likely and possible combinations of staff and patients. Ideally, the probability distribution should be a single full height column at $P_{a}$ equals 1.0 such that $\mathrm{P}_{\mathrm{D}}$ equals 0.0 . However, as the number of staff increases, the law of diminishing returns may apply and there is a cost/benefit balance to be made between staff costs and increased observation of fire. This balance should also be considered in the context of the provision and performance of automatic fire detection systems, but this is beyond the scope of this paper.

\section{Boolean addition}

Therefore, to assess the efficiency of various combinations, three other cases were analysed:

$$
\begin{array}{ll}
\text { 3. } & 2 \text { staff } \\
\text { 4. } & 3 \text { staff } \\
\text { 5. } & 2 \text { staff and patients }
\end{array}
$$

Cases 3 and 4 do not consider the contribution of patients since it may be politically unacceptable to base standards for a public building, like a hospital, on the performance of occupants who are not staff. However, patients can and do observe fires and so for the purposes of comparison with historical data, case 5 more closely reflects the actual norm. All cases assume that the number of fires detected by visitors is negligible and the statistics tend to support this [5] [6].

The probability distributions for cases 1 and 2 were combined using Boolean addition in both axes such that when two distributions were combined:

$$
\mathrm{P}=2 \mathrm{P}-\mathrm{P}^{2}
$$


and when three distributions were combined:

$$
\mathrm{P}^{\prime \prime}=3 \mathrm{P}-3 \mathrm{P}^{2}+\mathrm{P}^{3}
$$

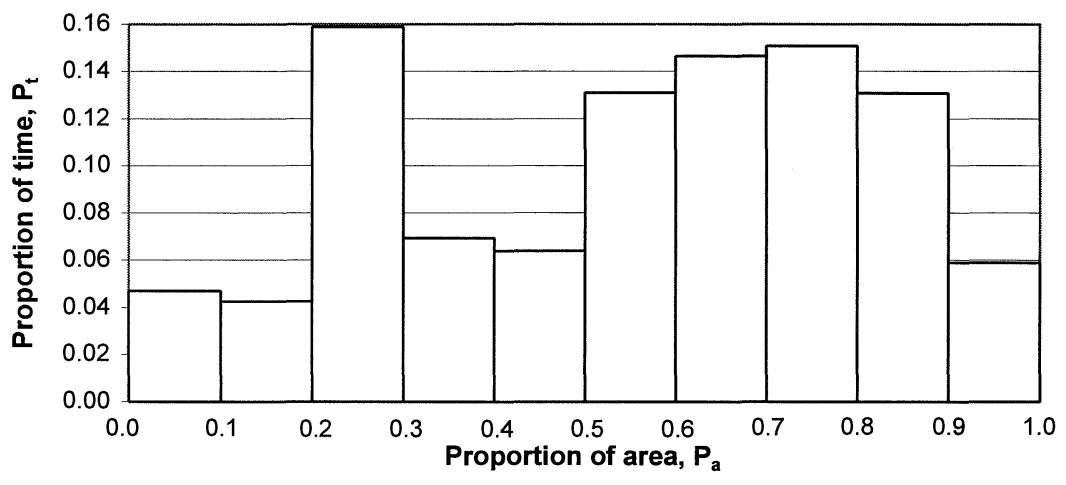

Figure 5 - Observation probability distribution for case 3 - two staff

At each stage the probability distribution was redistributed into the area classifications and normalised as appropriate. Normalising was necessary since people cannot observe in areas or during time that does not exist.

Figures 5, 6 and 7 show the probability distributions for the three cases. In all three cases it can be seen that the distributions have moved to the right indicating, as might be expected, an increased probability that a fire would be observed by staff and/or patients.

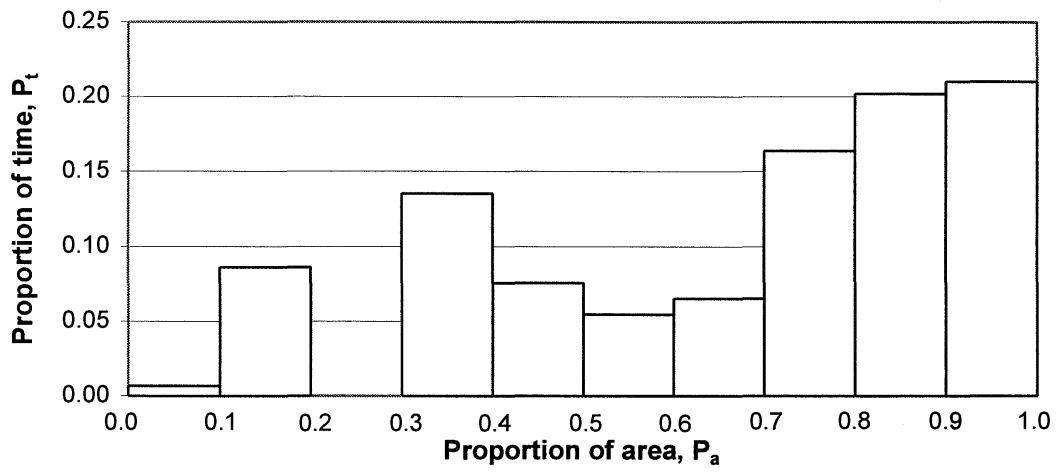

Figure 6 - Observation probability- distribution for case 4 - three staff 


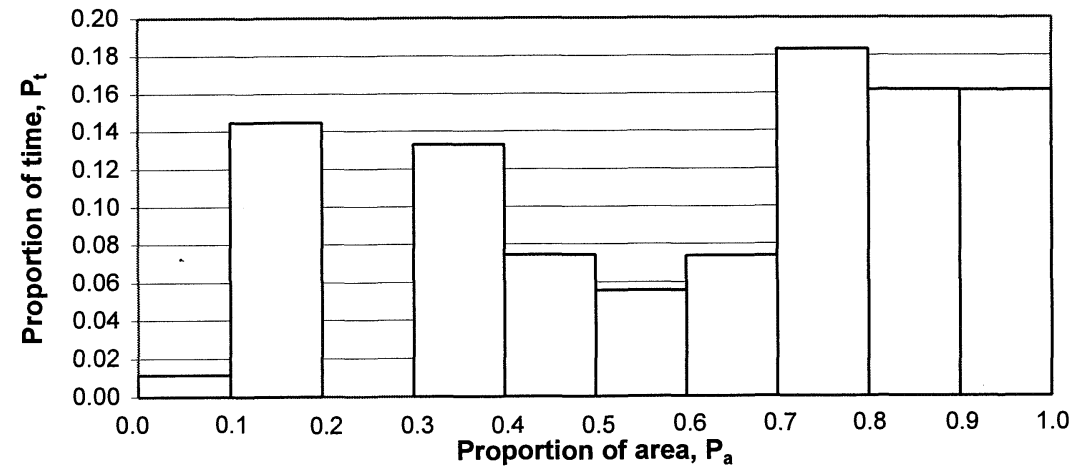

Figure 7 - Observation probability distribution for case 5 - two staff and patients

\section{DISCUSSION}

Table 2 shows the various values of $P_{D}$ and the resultant values of $P_{f}$ from the fault tree analysis.

The range of values for the probability that 'staff (and/or patients) will not be present (and/or alert) to detect a fire', $\mathrm{P}_{\mathrm{D}}$ is from 0.87 to 0.39 . The probability of failure for one staff member, 0.64 is lower than that for the patients, 0.87 . This is probably due to the fact that wards are designed for observation by staff rather than patients and that staff are awake on duty 24 hours, whereas, patients may be asleep or under sedation. However, it is worth noting that the data for patients is based on the majority and does not take into account circumstances when all but one patient may not be alert in say a six bedded bay.

\section{TABLE 2 - Summary of results}

\begin{tabular}{|l|l|l|l|}
\hline Case No. & Case & $\mathbf{P}_{\mathbf{D}}$ & $\mathbf{P}_{\mathbf{f}}$ \\
\hline 1 & 1 Staff & 0.64 & Not applicable \\
2 & Patients & 0.87 & Not applicable \\
3 & 2 Staff & 0.45 & 0.37 \\
4 & 3 Staff & 0.34 & 0.28 \\
5 & 2 Staff \& Patients & 0.39 & 0.32 \\
\hline
\end{tabular}

Note: $P_{f}$ is used to assess current standards and so cases 1 and 2 are not applicable 
If two staff are present rather than one, the probability of failure of staff to detect a fire, $\mathrm{P}_{\mathrm{D}}$ reduces from 0.64 to 0.45 . This is a significant reduction which is already the situation on most wards due to the requirements of clinical care and FIRECODE. Similarly, the probability of failure reduces from 0.45 to 0.34 when three rather than two staff are present. This difference is reflected in the overall conditional probability for failure to detect a fire on a ward within 5 minutes of ignition, $\mathrm{P}_{\mathrm{f}}$ of 0.37 and 0.28 (respectively). However, this reduction is only likely to be cost effective where clinical care necessitates three staff.

For the most realistic case 5 (ie two staff and patients), the probability that patients and staff will fail to detect a fire, $P_{D}$ is 0.39 . This lies between the cases for two and three staff and it is clear that, although the contribution of patients is small relative to that of staff, it is, by definition, beneficial and cost effective.

When the overall conditional probability for failure to detect a fire on ward within 5 minutes of ignition, $\mathrm{P}_{\mathrm{f}}$ is calculated for case 5 the value becomes 0.32 . The value implied by the fire report data [5] is less than half this at 0.14 . There may be several reasons for this:

The figures for automatic fire detection systems are not hospital specific, neglect the detection of fires in adjacent areas and the failure on demand is at the pessimistic end of the range.

The value for the failure of staff when present to detect a fire is also a generic figure for the performance of routine observations by trained staff.

The proportion of fires detected in 5 minutes or less is a subjective estimate by investigating officers.

The proportion of the ward observable by a member of staff is also a subjective estimate based on the potential development of a fire and the sensory performance (especially olfactory) of those present.

The sample for the study of staff observation of fires was relatively small compared to the size and diversity of the NHS.

The comparison also assumes that the probability of a fire occurring is the same throughout a ward. This is unlikely to be the case but there is little data which could help assess the likely effect that this may have on the result.

These are all areas worthy of further study in the quest to understand the mechanisms of fire detection and so help ensure continued fire safety of patients and other occupants of healthcare buildings. However, the relative values predicted from the analyses are still significant in informing decision on policy and standards. 


\section{CONCLUSIONS}

This simple example of fault tree analysis has demonstrated that it can be a very useful tool to aid decision making in the specification of fire protection. It could be particularly valuable in the conduct of cost benefit studies, the assessment of trade-offs and the provision of protection in circumstances where, for some reason, full compliance with FIRECODE [2] is not practicable.

Observation by people as a means of detecting fires can in specific circumstances be very effective. Thus, for the investigation carried out on staff observation; staff spent 75 per cent of their time undertaking duties that would facilitate the detect of fires, in locations where they could observe more than 30 per cent of the ward. This provides a greater understanding why the historical data indicates that staff observation of fire is so effective.

Comparison between fire report data and the fault tree analysis is encouraging but further work is needed. Areas of particular interest are; increasing the sample size (ie 300 out of about $10^{9}$ staff hours per year in the NHS) of the staff observation study and investigating the failure on demand of staff in an area to detect a fire. The latter will also study the effect that task type has on the ability to detect fires. Further analysis is also being undertaken with regard to the effects of different ward designs and the optimum provision of automatic fire detection. 


\section{REFERENCES}

1. McCormick N.J., Reliability and risk analysis, Academic Press, 1981, USA

2. FIRECODE, NHS Estates, Department of Health, HMSO, UK

3. Charters D.A., Quantified assessment of hospital fire risks, Interflam '96 Conference Proceedings, Interscience Communications, 1996, UK

4. Charters D.A. and Smith F.M., The effects of materials on fire hazards and fire risk assessment, Warrington, AEA Technology, C438/017, 1992, UK

5. FIRECODE, Fire Practice Note 9, NHS Healthcare fire statistics 1994/5, HMSO, 1996, UK

6. Fire Statistics United Kingdom 1993, Home Office, 1996, UK

7. Health Facilities Note 9, Fire safety - cost or benefit?, HMSO, 1995, UK

8. Finucane M. and Pinkney D., Reliability of fire protection and detection systems, Safety and Reliability Directorate, AEA Technology, SRD R431, HMSO, 1988, UK

9. Williams J., HEART: A proposed method for assessing and reducing human error, Proceedings of the 9th Advances in Reliability Technology Symposium, Bradford, 1986, UK

10. Barnett J.R. et al., Draft report on the observation of fires by staff in UK hospitals, Private communication, Worcester Polytechnic Institute, 1996, USA

\section{ACKNOWLEDGEMENT}

The authors would like to acknowledge the help of the patients and staff of the Royal London Hospitals NHS Trust and in particular Barry Clarke, the Risk Manager, without whose assistance the study would not have been possible. 